\title{
After 10 Years: Back to Where We Began
}

\author{
C. C. Chancey \\ University of Northern lowa \\ Cedar Falls, lowa 50614-0150 USA
}

Reprinted from Vol. 1, No. 1 (June 2002): Undergraduates in the United States and elsewhere have become increasingly involved in scientific research during the past decade. A number of excellent organizations have worked hard to promote this outcome, Project Kaleidoscope and the Council on Undergraduate Research in particular. In the U.S., the National Science Foundation and the National Institutes of Health have been strong institutional proponents of undergraduate involvement in research. Interdisciplinary societies, such as Sigma Xi, The Scientific Research Society, have stepped forward to provide grants for student research, and corporations, such as Merck, have underwritten significant undergraduate research programs. Disciplinary societies, such as the American Chemical Society, publish undergraduate research journals for student research in their areas. College faculty members have been ceaseless in mentoring undergraduate researchers and including them as authors on their research articles in the standard literature. The bar can always be raised, but the present is a good time for undergraduates who wish to learn science by doing it.

Given this near nirvana, is there role for a new interdisciplinary, undergraduate research journal? I think there is, and the American Journal of Undergraduate Research takes its first steps committed to promoting several outcomes.

First, this journal seeks to help undergraduate researchers become better scientists by helping them become better writers and expositors of science. We believe that undergraduates should participate fully in writing research articles and in responding to comments from referees. Students are best helped when they take the lead as senior authors. This requires a more tutorial review process than is typically provided by mainstream research journals. AJUR is committed to providing a review process that is fully professional but consciously tutorial. The journal understands the tight timescale for many undergraduate researchers, and we will strive to provide quick initial reviews (3 weeks after receipt).

Second, AJUR seeks to provide a forum that is broader than a single discipline. The journal will happily publish articles from the standard disciplines but it also encourages undergraduates to submit papers that are interdisciplinary or that are not easily categorized within the older domains.

Third, this journal will encourage submissions from undergraduates engaged in scientific or technical researches wherever they may be in the world. It is a truism that science is international, and all undergraduates will be served by an editorial board that is international in scope, as AJUR's is. This journal thinks that undergraduates can better appreciate science by seeing what the international norms are for student research. We believe that this journal can help students make contact with others engaged in similar researches elsewhere in the world-all to the benefit of all undergraduate science students.

Fourth, AJUR offers a review process that provides an assessment of research beyond that provided on individual college campuses. We hope that AJUR's network of national and international editors and referees will help promote a high international standard for undergraduatelevel research presentations.

Finally, an endeavor like AJUR depends on a network of science, technology, engineering, mathematics, and education professionals. College faculty across the U.S. and from several countries have formed a preliminary network to produce this first issue. AJUR's growth and its ability to meet its goals will require a continual elaboration and strengthening of this network. I hope this network of faculty will provide them and their students with increased opportunities for participation in the wide arena of science. 